\title{
EFFECTS OF ATOMIC OXYGEN ON POLYMERIC MATERIALS FLOWN ON EOIM-3
}

\author{
Rachel R. Kamenetzky \\ Roger C. Linton \\ Miria M. Finckenor \\ Jason A. Vaughn \\ Space Environment Effects \\ Marshall Space Flight Center, AL 35812
}

\section{ABSTRACT}

Diverse polymeric materials, including several variations of Kapton, were flown on STS46 as part of the Evaluation of Oxygen Interaction with Materials Experiment (EOIM-3). These materials were flown in the cargo bay and exposed to the space environment July 31 - August 8,1992 , including 40 hours of direct atomic oxygen impingement. The atomic oxygen exposure was approximately $2.2 \times 10^{20}$ atoms $/ \mathrm{cm}^{2}$.

Polymeric materials flown on EOIM-3 include coated and uncoated Kapton, Tefzel ETFE, Lexan, FEP and TFE Teflon, bulk Halar and PEEK, S383 silicone and Viton elastomeric seal material. Analyses performed included thickness measurements using Dektak and eddy current methods, mass loss, resistance, permeability, hardness, and FTIR. The effects of stress and the space environment on Kapton were also evaluated.

Previous EOIM missions on STS-5 and STS-8 and the Long Duration Exposure Facility also contained polymeric material samples. Data from these previous flights are shown for comparison, as well as ground simulation of space environment effects using both thermal energy flow tubes and $5 \mathrm{eV}$ neutral atomic oxygen beam facilities. Reaction efficiencies for the various atomic oxygen exposure conditions are discussed.

\section{INTRODUCTION}

Material durability in the space environment is a major concern of spacecraft designers. Over the past decade, scientists and engineers have worked to achieve a better understanding of the space environment and its effect on potential engineering materials and material processes. The Long Duration Exposure Facility (LDEF) has provided a wealth of data on long term material durability and survivability ${ }^{1}$; however, the cost in terms of time and dollars for this type of testing is often prohibitive. As a result, spacecraft designers must often rely on data generated from short term Space Shuttle missions and ground simulations to predict long term material stability. The Evaluation of Oxygen Interactions with Materials (EOIM) flight experiments were a series of Space Shuttle exposed payloads designed to evaluate the effects of low earth orbit (LEO) exposure on materials of spacecraft design interest and, if feasible, predict long term material life. 
The Space Shuttle mission STS-46 payload included the third EOIM flight experiment (fig. 1). This flight exposed a variety of materials including numerous thin film and bulk polymeric materials to the space environment July 31 through August 8, 1992. Polymeric materials in general have been shown to be highly sensitive to atomic oxygen, the predominate chemical species for $\mathrm{LEO}^{2}$. The Marshall Space Flight Center (MSFC) array of polymer samples included thin films of Kapton, carbon impregnated Black Kapton, coated Kapton, Tefzel (copolymer of tetrafluoroethylene and ethylene), FEP and TFE Teflons, and Lexan. MSFC bulk polymer specimens included Halar (a copolymer of chlorotrifluoroethylene and ethylene), polyetheretherketone (PEEK), silicone S383, and Viton (a copolymer of vinylidene fluoride and hexafluoroprene).

\section{SPACE ENVIRONMENT}

The EOIM-3 payload was exposed to LEO from within the ram oriented open cargo bay of the Space Shuttle as it orbited the Earth at an altitude of 123-124 nautical miles. Although this exposure provided the majority of the total EOIM-3 atomic oxygen fluence, additional atomic oxygen was incurred during the deployment, release, and station-keeping of the European Retrievable Carrier (EURECA) such that total accumulated atomic oxygen fluence levels for the EOIM-3 flight experiment were determined to be $2.2 \times 10^{20}$ atoms $/ \mathrm{cm}^{2}$. In addition, samples were exposed to approximately 30.6 sun hours of solar ultraviolet (UV) radiation, of which 7.6 sun hours were synergistic with atomic oxygen impingement. Thermal extremes ranged from -5 ${ }^{\circ} \mathrm{C}$ to $80^{\circ} \mathrm{C}$ for the passively exposed trays. Particulate radiation was negligible, and there was no indication of significant micrometeoroid impact or space debris damage.

\section{EOIM-3 FLIGHT EXPERIMENT DESCRIPTION}

Thin film specimens of Kapton H, Kapton HN, Kapton with various protective coatings, Black Kapton, Tefzel, and Lexan as well as bulk polymeric Halar and PEEK specimens were exposed on MSFC EOIM-3 passive tray 04. The coated specimens consisted of plasma polymerized hexamethyl disiloxane (HMDS)/Teflon TFE over Kapton and indium tin oxide (ITO) over aluminized Kapton. Two different ratios of HMDS to TFE were used, 40:2 and 40:5. The polymer samples were configured such that many were partially shielded from atomic oxygen by way of "half-moon" aluminum covers or wire mesh (fig. 2). Thin films of Kapton H, Kapton HN (from LeRC and JSC round-robin supply), carbon impregnated Black Kapton, FEP Teflon and TFE Teflon were also exposed on the actively heated $60^{\circ} \mathrm{C}$ and $120^{\circ} \mathrm{C}$ trays. One inch diameter samples of bulk S383 silicone and Viton elastomeric seal material samples were also flown on the $60^{\circ} \mathrm{C}$ heated tray.

In addition to the passive and heated tray polymer specimens, sheets of 2 mil thick Kapton $\mathrm{HN}$ were exposed in fixtures designed to maintain a constant pre-load mechanical stress (the uniform stress fixtures) by way of a spring load mechanism and on fixtures designed to provide only an initial pre-load (the static stress fixtures). Two uniform stress fixtures (fig. 3 ) were flown, with the Kapton specimens loaded to a pre-flight stress of 219 psi and 375 psi. 
Beneath each loaded Kapton specimen, a separate Kapton sample was fixed to the base plate of the fixture to monitor reflected/scattered atomic oxygen. Two static stress fixtures (fig. 4) were flown with a "finger-tight" load placed on the Kapton specimens. Each Kapton flight specimen was coated on the backside with an aluminum grid pattern to aid in mapping thickness location measurements.

Atomic oxygen reactivity values were calculated based on changes in mass, thickness, and resistivity of the polymer films. Flight samples and ground control samples were stored in desiccators during the post flight analysis period. Kapton samples were placed under vacuum for a minimum of twenty minutes prior to taking mass measurements, with the final mass value extrapolated to time zero. All mass measurements were made using a Mettler AT250 balance. Thickness measurements were made using either a Sloan Dektak IIA probe, a Zeiss light section microscope, or a UPA Dermitron Thickness Tester D-8. Resistivity measurements were made using a Magne-Tron model M-700 four point probe. A scanning electron microscope (SEM) was used for surface morphology imaging of the film and bulk polymer specimens. Seal materials were evaluated for changes in permeability using a Varian 936-SP helium leak detector and changes in hardness using a Shore A hardness tester.

\section{GROUND SIMULATION EXPERIMENTS DESCRIPTION}

In order to better evaluate the validity of ground simulated atomic oxygen effects on materials, Halar, PEEK and FEP Teflon coated with Inconel and silver (AgFEP) polymer samples were tested for atomic oxygen sensitivity in the Princeton Plasma Physics Laboratory (PPPL) 5 eV Neutral Atomic Oxygen Facility and in the MSFC EH15 Advanced Atomic Oxygen Drift Tube Simulator (AODTS). These samples were then evaluated against their counterpart EOIM-3 flight samples. The PPPL facility produces a neutral $5 \mathrm{eV}$ atomic oxygen beam via a plasma generated using a $2.45 \mathrm{GHz}$, radio frequency (RF) field that is neutralized by an inelastic collision with a tantalum plate. During the production of the atomic oxygen plasma, the system produces vacuum ultraviolet (VUV) radiation at the atomic oxygen resonant peak of $130 \mathrm{~nm}$. In this particular test series, the polymers were exposed to an atomic oxygen fluence of approximately $7.2 \times 10^{20}$ atoms $/ \mathrm{cm}^{2}$ and a VUV irradiance of approximately 8000 equivalent sun hours (ESH). The AODTS facility produces a thermal atomic oxygen plasma generated by a 14.7 MHz RF field. Samples are exposed outside of the RF field, eliminating unwanted sample heating and exposure to any plasma charged particles. In one particular test series, samples of Halar, PEEK and AgFEP were exposed to an atomic oxygen fluence of approximately $7.1 \times 10^{22}$ atoms $/ \mathrm{cm}^{2}$. Additional samples of Halar and PEEK turned $180^{\circ}$ from the atomic oxygen drift direction received a fluence of $2.1 \times 10^{22}$ atoms $/ \mathrm{cm}^{2}$. In a second test series ${ }^{4}$, samples of S383 and Viton were exposed to $1.3 \times 10^{22}$ atoms $/ \mathrm{cm}^{2}$ of thermal atomic oxygen in the AODTS system. Additional samples were exposed to 1714.5 equivalent sun hours (ESH) of ultraviolet radiation using a $\mathrm{Hg}-\mathrm{Xe} 1 \mathrm{KW}$ att source followed by an accumulated fluence of $1.3 \times 10^{22}$ atoms $/ \mathrm{cm}^{2}$ of thermal atomic oxygen in the AODTS system. 


\section{THIN FILM EVALUATION RESULTS}

Atomic oxygen reactivity values for the EOIM-3 thin films are shown in table 1 along with values taken from samples flown on LDEF experiment A0171 and Shuttle missions STS-5, 8 , and -41 . In addition, reactivity values for samples exposed in the PPPL facility and MSFC AODTS facility are shown where available for comparison. Mass loss and resistivity measurements made on the EOIM-3 Kapton samples with protective coatings indicated that the samples were not significantly affected by atomic oxygen exposure. Reactivity values greater than $3.0 \times 10^{-24} \mathrm{~cm}^{3} /$ atom were calculated for the EOIM-3 Kapton $\mathrm{H}$ and Kapton $\mathrm{HN}$ samples. These reaction efficiencies are slightly higher than values previously reported for EOIM missions ${ }^{3}$. In general, Kapton $\mathrm{H}$ specimens had a slightly higher reactivity value than Kapton HN. Black Kapton samples were generally less reactive than normal Kapton, with reactivity values on the order of 2.1 to $2.5 \times 10^{-24} \mathrm{~cm}^{3} /$ atom. Reactivity values for EOIM-3 Lexan samples were somewhat higher than values generated from STS-41 flight data.

EOIM-3 TFE and FEP samples indicated reactivity values an order of magnitude lower than LDEF A0171 values, most probably due to differences in ultraviolet radiation exposure levels. By way of comparison, reactivity values of silverized Teflon tape samples exposed to atomic oxygen and 8000 ESH of VUV radiation in the PPPL facility showed a marked increase in atomic oxygen sensitivity, while samples exposed only to thermal atomic oxygen in the AODTS indicated reactivity values that were more in agreement with the flight samples exposed to low levels of UV radiation.

Samples exposed at elevated temperatures generally showed an increase in atomic oxygen reactivity. While FTIR analysis did not show any structural changes in the Teflon samples due to LEO exposure or elevated temperatures, when compared to ground controls, changes in percent transmission were noted (figs. 5 and 6).

\section{BULK POLYMER EVALUATION RESULTS}

Reactivity values for the EOIM-3 bulk Halar and bulk PEEK flight specimens as well as for LDEF A0171, STS-41, PPPL, and AODTS are shown in table 1. EOIM-3 and LDEF values are in fairly good agreement, but are somewhat higher in value than the STS-41 results for Halar and somewhat lower in value than the STS-41 results for PEEK. In both cases, PPPL values tended to be somewhat higher, while AODTS values were lower. FTIR analysis did not show any structural changes in the Halar or PEEK samples due to LEO exposure or PPPL exposure, when compared to ground controls, though changes in percent transmission were noted (figs. 7 and 8). SEM photographs (fig. 9) of the exposed region of Halar and PEEK specimens from EOIM-3, LDEF A0171, and PPPL show distinct atomic oxygen erosion characteristics. Samples exposed to thermal atomic oxygen in the AODTS facility lacked the distinctive erosion structures found in samples exposed to $5 \mathrm{eV}$ atomic oxygen.

EOIM-3 S383 and Viton seal material, exposed on the $60^{\circ}$ heated tray, were visibly unchanged. By comparison, samples exposed to ground simulated ultraviolet radiation and AODTS generated atomic oxygen were visibly changed in the exposed region. Ground tested S383 exposed to atomic oxygen appeared glossy in the exposed region. S383 samples exposed 
to ultraviolet radiation followed by atomic oxygen appeared glossy and showed evidence of surface microcracking. Ground tested Viton became diffuse in appearance when exposed to ground simulated atomic oxygen. Viton samples exposed to ultraviolet radiation followed by atomic oxygen appeared grayish-white in the exposed region in contrast to the protected shiny black unexposed region.

Shore A hardness measurements (table 2) indicated a slight increase in surface hardness for both S383 and Viton samples due to the EOIM-3 low earth orbit exposure. Permeability data for the EOIM-3 S383 and Viton showed no significant change.

EOIM-3 S383 and Viton reflectance measurements from $250 \mathrm{~nm}$ to $2500 \mathrm{~nm}$ are shown in Figures 10 and 11. S383 solar absorptance and infrared emittance values (table 2) showed little change due to exposure, while the Viton flight specimen showed a $2.2 \%$ increase in solar absorptance and a $3.5 \%$ increase in infrared emittance (table 2). These changes are in fairly good agreement with data taken from ground exposed S383 and Viton specimens. FTIR analysis on the EOIM-3 S383 specimen (fig. 12) showed only slight structural changes, with the appearance of the early development of a carbonyl functional group (1633 $\left.\mathrm{cm}^{-1}\right)$ and the development of $\mathrm{O}-\mathrm{H}$ bonds ( 3000 to $3500 \mathrm{~cm}^{-1}$ ). This is in good agreement with FTIR spectra taken on ground tested S383. No new structures were noted for the EOIM-3 Viton specimen (fig. 13), though a general shift in transmission over the entire scan range of 700 to $4000 \mathrm{~cm}^{-1}$ was noted. This transmission shift was also noted for similar samples exposed in ground testing.

Short wave blacklight observations revealed changes in fluorescence for both the S383 and Viton samples. The S383 flight sample appeared yellow/orange in the exposed region in contrast to the natural red of the unexposed region. The Viton sample appeared pea green in the exposed region, in contrast to the natural black coloring of the unexposed region. Fluorescence scans of the EOIM-3 S383 and Viton specimens (figs. 14 and 15) clearly showed distinct changes in both relative intensity and emission wavelength for the exposed sample region as compared to the unexposed region. Fluorescence scans on ground exposed S383 showed similar stimulated emission $^{4}$. Fluorescence scans on ground exposed Viton specimens varied, dependent on exposure conditions. Ground simulated atomic oxygen exposure resulted in a grey ash on the Viton samples, interfering with good fluorescence measurements. Ultraviolet radiation exposure has quenched the fluorescent properties of the Viton in ground simulation ${ }^{4}$. Batch variations in Viton fluorescence have also been noted.

\section{KAPTON UNIFORM AND STATIC STRESS FIXTURES}

The Kapton uniform stress and static stress fixtures were loaded with 2 mil Kapton HN on October 24, 1991 in preparation for the EOIM-3 flight experiment. The Kapton from all four fixtures appeared diffuse in the exposed regions in contrast to the typical transparent nature of virgin Kapton film. Because of this diffuse scatter in the exposed regions, post-flight light section microscope analysis could not be used to effectively map any thickness changes in the Kapton flight specimens. In addition, post-flight observations showed a white contaminate smear on the Kapton specimens loaded on both static stress fixtures. Efforts to map thickness changes by other methods are continuing.

The two uniform stress fixtures were flown with the Kapton specimens loaded to a preflight load of 1.9 pounds and 2.3 pounds. The exposed Kapton was removed from the fixtures 
on July 12, 1993 at which time the measured load on the Kapton specimens was recorded as 1.4 pounds and 2.0 pounds, respectively. Mass loss measurements on the Kapton indicated reaction efficiencies of $3.2 \times 10^{-24}$ and $3.3 \times 10^{-24} \mathrm{~cm}^{3} /$ atom. These values are in agreement with values generated based on mass loss for Kapton specimens exposed on the EOIM-3 passive trays (table 1). Mass loss data on the Kapton specimens removed from the two static fixtures, which were pre-loaded to a finger-tight condition, indicated in both cases an atomic oxygen reaction efficiency of $3.5 \times 10^{-24} \mathrm{~cm}^{3} /$ atom, which, despite the aforementioned contamination, is somewhat higher than the values generated from the EOIM-3 passive tray samples.

Well-defined rectangular diffuse areas were also observed during post-flight evaluation along both edges of the Kapton specimens exposed as part of the atomic oxygen monitoring packs that were attached to the base plate of each of the two uniform stress fixtures (fig. 3). Based on Kapton mass loss, measured diffuse area and an assumed reaction efficiency of $3.3 \mathrm{x}$ $10^{-24} \mathrm{~cm}^{3} /$ atom, the two fixture base plates received an atomic oxygen fluence of $3.5 \times 10^{19}$ atoms $/ \mathrm{cm}^{2}$ and $6.0 \times 10^{19}$ atoms $/ \mathrm{cm}^{2}$.

\section{INTERIM CONCLUSIONS}

The HMDS/TFE and ITO coatings appeared to do a good job of protecting the underlying Kapton from atomic oxygen attack. All uncoated EOIM-3 polymers showed evidence of atomic oxygen erosion. Atomic oxygen reactivity values for the EOIM-3 polymers varied in degree of agreement with values generated from previous flight data. Evaluation techniques (i.e. mass loss versus thickness change) also appear to be a factor in gauging the degree of reactivity value agreement. In general, reactivity values based on mass loss appear in fairly good agreement with LDEF A0171 values for Halar and PEEK. Reactivity values for the EOIM-3 Kapton specimens, though consistent for all the EOIM-3 specimens, are somewhat higher than values reported from previous flight experiments. The reason for the higher Kapton reactivity values is still undetermined. Polymers exposed on the heated trays had higher reactivity values than comparable samples exposed on the passive trays.

The atomic oxygen reaction efficiencies of some of these flight samples exposed on EOIM-3 are considerably less than values determined from exposure in the Princeton AO beam facility. Polymer samples exposed in the PPPL facility generally react with efficiency comparable to that experienced by similar materials in LEO, such as Kapton, black Kapton, polycarbonates, and polyethylene. Fluorocarbon materials such as Teflon have been found to be highly sensitive to the intrinsic vacuum ultraviolet (VUV - $130 \mathrm{~nm}$.) radiation of most AO beam facilities, including the PPPL facility by means of synergistic reaction with the radiation and atomic oxygen. The reaction efficiencies determined from beam facility exposures of these type materials are then proportional to the irradiation levels coincident with AO. The differences in AO reaction efficiencies of EOIM-3 samples of Halar and PEEK, which are also know to be UVsensitive, were less pronounced in comparison to the PPPL results. Polymers exposed to thermal energy atomic oxygen in the AODTS facility indicated reaction efficiencies ranging from 2 to 100 times less than polymers exposed to orbital atomic oxygen, as would be expected.

Mechanical and thermal properties of the EOIM-3 S383 and Viton seal materials were not greatly affected by the low earth orbit exposure. Seal permeability showed no significant change, while seal Shore A hardness increased only slightly for the S383 material. S383 solar absorptance and infrared emittance remained stable, while Viton showed an increase of 
approximately $2 \%$ in solar absorptance and $3.5 \%$ in infrared emittance. Fluorescence scans on both the S383 and Viton specimens indicated a stimulated fluorescence emission as a result of space exposure.

EOIM-3 Kapton HN specimens exposed to the space environment on the uniform stress fixtures with a mechanical pre-load indicated reactivity values comparable to Kapton $\mathrm{HN}$ specimens that were exposed without a pre-load. Kapton HN samples exposed on the static stress fixtures with only a finger tight load had reactivity values slightly higher than the passive tray specimens. As a result, no definitive conclusion can be drawn as to the effect of mechanical stress on atomic oxygen reaction efficiency. However, because the Kapton HN specimens that were exposed as part of the atomic oxygen monitoring packs indicated the presence of significant atomic oxygen impingement along the fixture base plates, total EOIM-3 atomic oxygen flux values might need to be re-evaluated.

\section{REFERENCES}

1. Levine, A.S., "LDEF - 69 Months in Space First Post-Retrieval Symposium, Parts 1, 2 and 3", NASA CP 3134, Kissimmee, Florida, June 2-8, 1991.

2. Visentine, James T., "Atomic Oxygen Effects Measurements for Shuttle Missions STS-8 and 41-G, Volume III", NASA TM 100459.

3. Leger, Lubert, Koontz, S., Visentine, J., and Hunton, D., "An Overview of the Evaluation of Oxygen Interaction with Materials III Experiment", LDEF Materials Results for Spacecraft Applications Conference, Huntsville, Alabama, October 26-28, 1992.

4. Linton, R. C., Finckenor, M. M., Kamenetzky, R. R. , and Gray, P., "Effects of Atomic Oxygen and Ultraviolet Radiation on Candidate Elastomeric Materials for Long Duration Missions, Test Series No. 1", NASA TM 108408. 


\begin{tabular}{|c|c|c|c|c|c|c|}
\hline \multicolumn{7}{|c|}{ Atomic Oxygen Reaction Efficiency $\times 10^{-24} \mathrm{~cm}^{3} /$ atom } \\
\hline Sample & STS-5 and-8 & MSFC STS-41 & LDEF A0171 & MSFC EOIM-3 & PPPL & AODTS \\
\hline $\begin{array}{l}\text { Halar } \\
\text { (Bulk) }\end{array}$ & & $\begin{array}{l}1.6^{(2)} \\
1.0^{(2)} \\
2.0^{(1)}\end{array}$ & $2.1^{(1)}$ & $\begin{array}{l}2.0^{(1)} \\
2.5^{(2)}\end{array}$ & $\begin{array}{l}3.2^{(1)} \\
3.4^{(1)} \\
3.1^{(2)} \\
3.0^{(2)}\end{array}$ & $\begin{array}{c}0.034^{(1)} \\
0.023^{(1)} \\
0.014^{(2)}\end{array}$ \\
\hline $\begin{array}{l}\text { Lexan } \\
\text { (Film) }\end{array}$ & . & $\begin{array}{l}3.6^{(2)} \\
1.3^{(1)}\end{array}$ & & $\begin{array}{l}3.6^{(2)} \\
4.8^{(1)} \\
4.0^{(1)} \\
\end{array}$ & & \\
\hline $\begin{array}{l}\text { PEEK } \\
\text { (Bulk) }\end{array}$ & & $4.7^{(1)}$ & $2.3^{(1)}$ & $\begin{array}{l}2.0^{(1)} \\
2.0^{(1)} \\
3.7^{(2)} \\
4.0^{(2)} \\
\end{array}$ & $\begin{array}{l}2.8^{(1)} \\
3.0^{(2)}\end{array}$ & $\begin{array}{l}0.11^{(1)} \\
0.12^{(1)}\end{array}$ \\
\hline $\begin{array}{l}\text { Tefzel } \\
\text { (Film) }\end{array}$ & & $0.20^{(1)}$ & & $\begin{array}{l}1.0^{(1)} \\
1.1^{(1)} \\
\end{array}$ & & \\
\hline $\begin{array}{l}\text { Kapton HN } \\
\text { (Film) }\end{array}$ & & $3.3^{(1)}$ & & $\begin{array}{c}3.3^{(1)} \\
2.9^{(1)} \\
4.3^{(1)} @ 120^{\circ} \mathrm{C} \\
\end{array}$ & & \\
\hline $\begin{array}{l}\text { Kapton } \mathbf{H} \\
\text { (Film) }\end{array}$ & $3.0^{(1)}$ & & & $\begin{array}{c}3.5^{(1)} \\
3.9^{(1)} \\
3.9^{(1)} @ 120^{\circ} \mathrm{C} \\
\end{array}$ & $3.4^{(1)}$ & \\
\hline $\begin{array}{l}\text { Black } \\
\text { Kapton } \\
\text { (Film) }\end{array}$ & & $\begin{array}{l}3.1^{(1)} \\
2.4^{(3)}\end{array}$ & & $\begin{array}{c}2.1^{(1)} \\
2.1^{(1)} \\
2.7^{(1)} @ 120{ }^{\circ} \mathrm{C} \\
2.3^{(3)} \\
2.3^{(3)} \\
\end{array}$ & & \\
\hline $\begin{array}{l}\text { TFE Teflon } \\
\text { (Film) }\end{array}$ & $<0.05$ & & $\begin{array}{c}0.20^{(2)} \\
\text { (Bulk Washers) }\end{array}$ & $\begin{array}{c}0.049^{(1)} @ 60^{\circ} \mathrm{C} \\
0.093^{(1)} @ 120^{\circ} \mathrm{C} \\
0.080^{(1)} @ 120^{\circ} \mathrm{C}\end{array}$ & & \\
\hline $\begin{array}{l}\text { FEP Teflon } \\
\text { (Film) }\end{array}$ & $<0.05$ & & $\begin{array}{c}0.35^{(2)} \\
<\mathrm{A} 0178>\end{array}$ & $\begin{array}{c}0.082^{(1)} @ 60^{\circ} \mathrm{C} \\
0.094^{(1)} @ 120^{\circ} \mathrm{C} \\
0.082^{(1)} @ 120^{\circ} \mathrm{C}\end{array}$ & $\begin{array}{c}6.6^{(1)} \\
5.9^{(2)} \\
<\text { AgFEP }\end{array}$ & $\begin{array}{c}0.023^{(1)} \\
0.023^{(2)} \\
<A g F E P>\end{array}$ \\
\hline
\end{tabular}

Atomic Reaction Efficiency

(1) Based on change in mass

(2) Based on change in thickness

(3) Based on resistivity measurement

Table 1

Atomic Oxygen Reaction Efficiencies of Polymers 


\begin{tabular}{||l|c|c|c|c||}
\hline Sample & Shore A Hardness & $\begin{array}{c}\text { Permeability } \\
(\mathrm{cc} / \mathrm{s} \mathrm{He})\end{array}$ & Solar Absorptance & Thermal Emittance \\
\hline S383 Control & $70.13 \pm 0.18$ & 2.90 & 0.750 & 0.92 \\
\hline S383 Flight & $71.68 \pm 0.27$ & 2.81 & 0.751 & 0.91 \\
\hline Viton Control & $76.29 \pm 0.12$ & 2.43 & 0.938 & 0.86 \\
\hline Viton Flight & $76.86 \pm 0.13$ & 2.53 & 0.959 & 0.89 \\
\hline
\end{tabular}

Table 2

EOIM-3 Seal Materials Data 


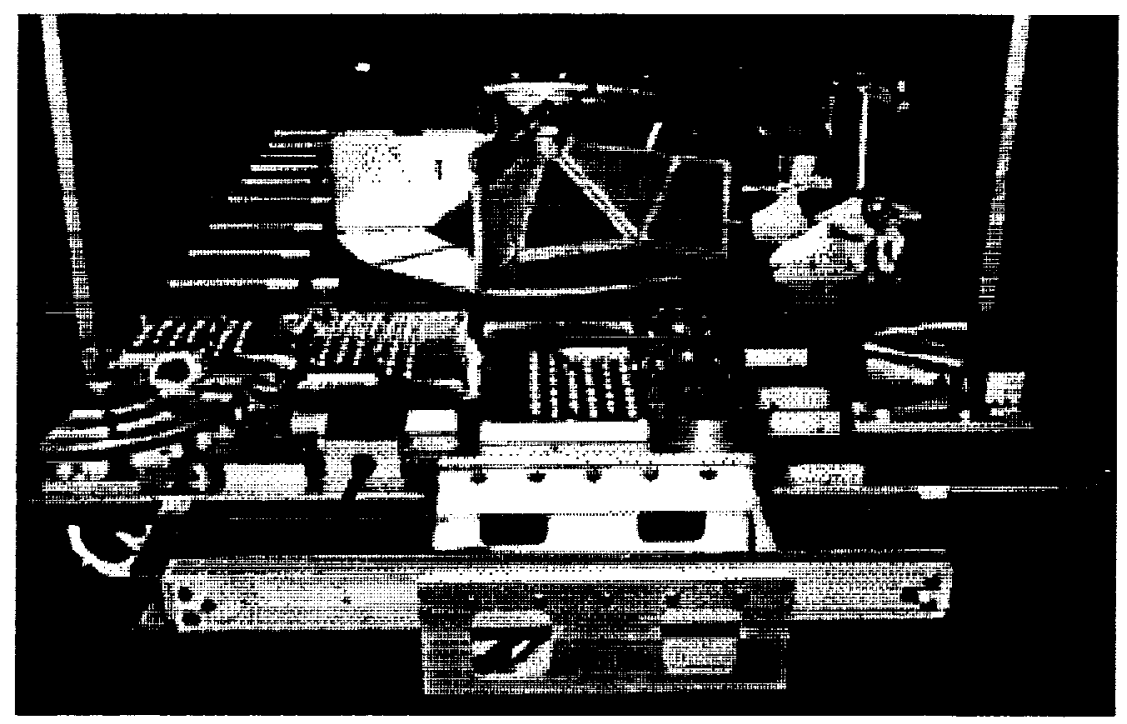

Figure 1. Photograph of EOIM-3 experiment pallet.

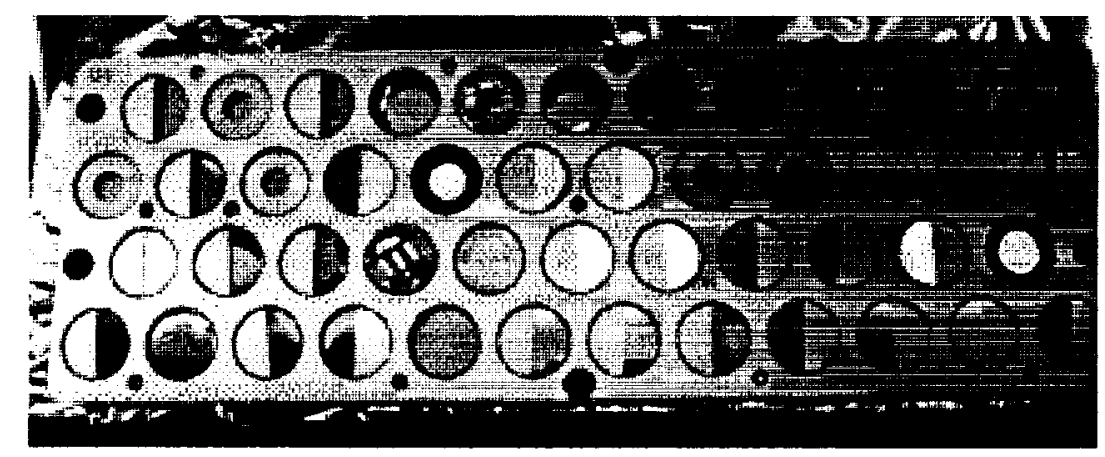

Figure 2. EOIM-3 passive tray 04 polymer samples.

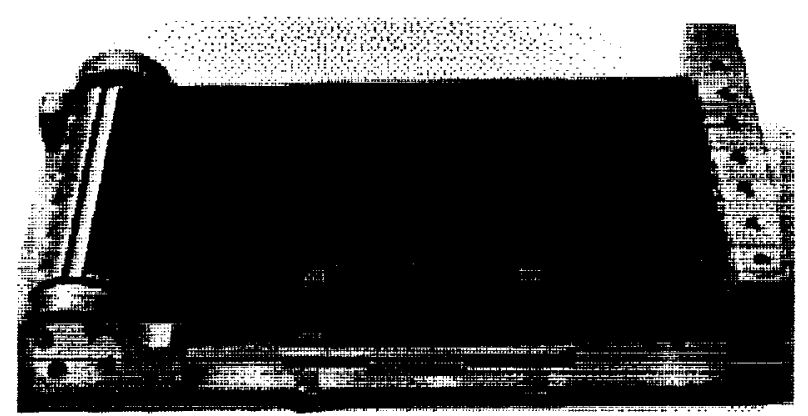

Figure 3. Post-flight photograph of MSFC uniform stress fixture showing loaded Kapton specimen. The Kapton specimen under the loaded specimen was used to evaluate atomic oxygen scatter / reflection. 


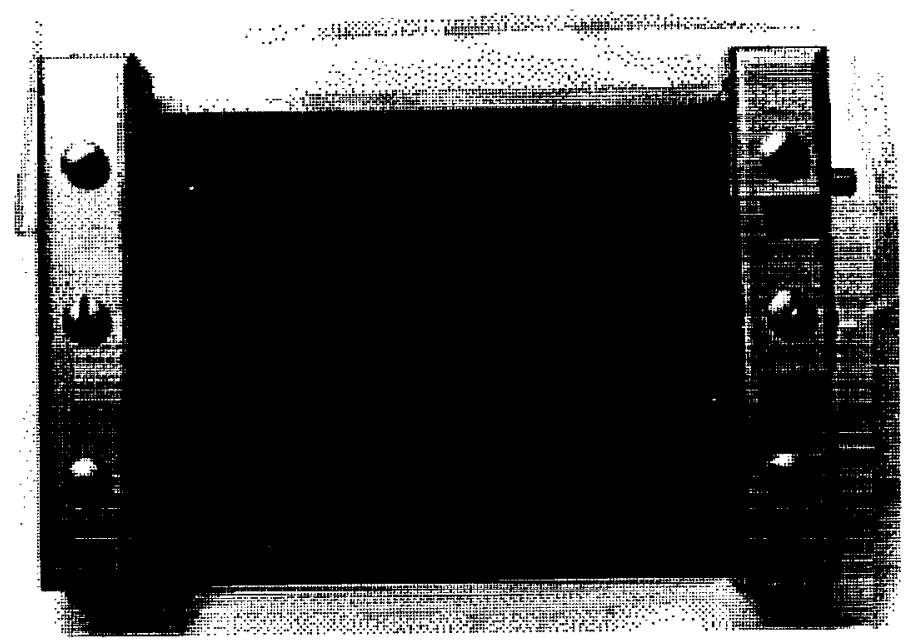

Figure 4. Post-flight photograph of MSFC static stress fixture showing loaded Kapton specimen.

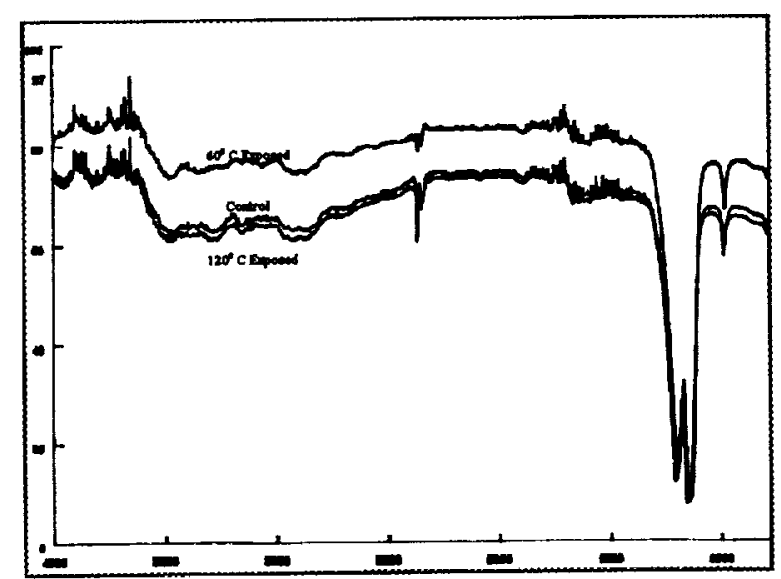

Figure 5. FTIR of EOIM-3 FEP Teflon showing percent transmission as a function of wavenumber $\left(\mathrm{cm}^{-1}\right)$.

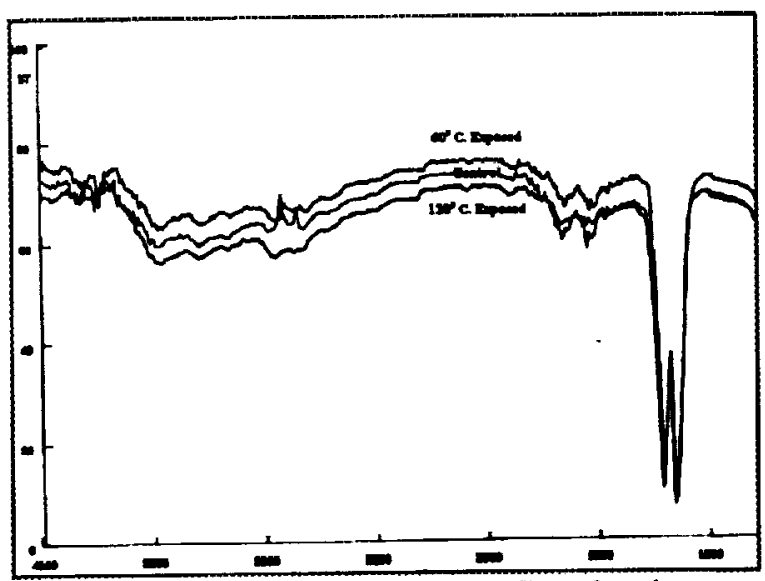

Figure 6. FTIR of EOIM-3 TFE Teflon showing changes in percent transmission as a function of wavenumber $\left(\mathrm{cm}^{-1}\right)$.

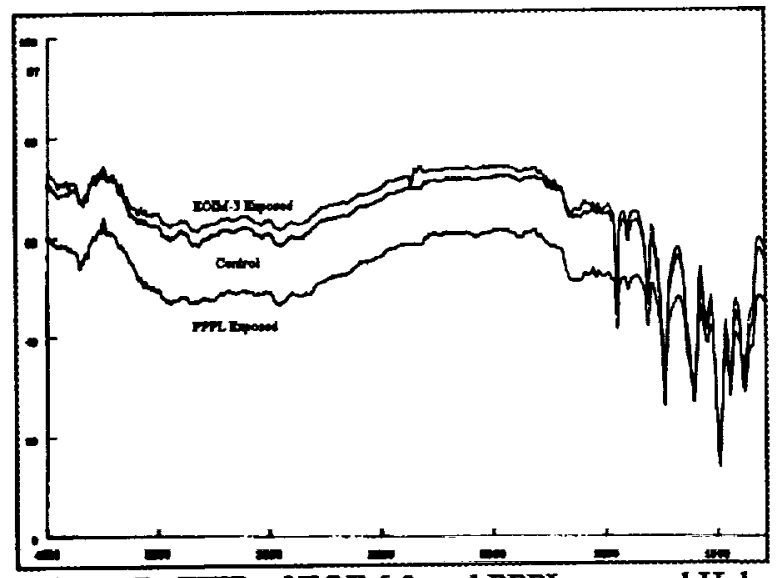

Figure 7. FTIR of EOIM-3 and PPPL exposed Halar showing percent transmission as a function of wavenumber $\left(\mathrm{cm}^{-1}\right)$.

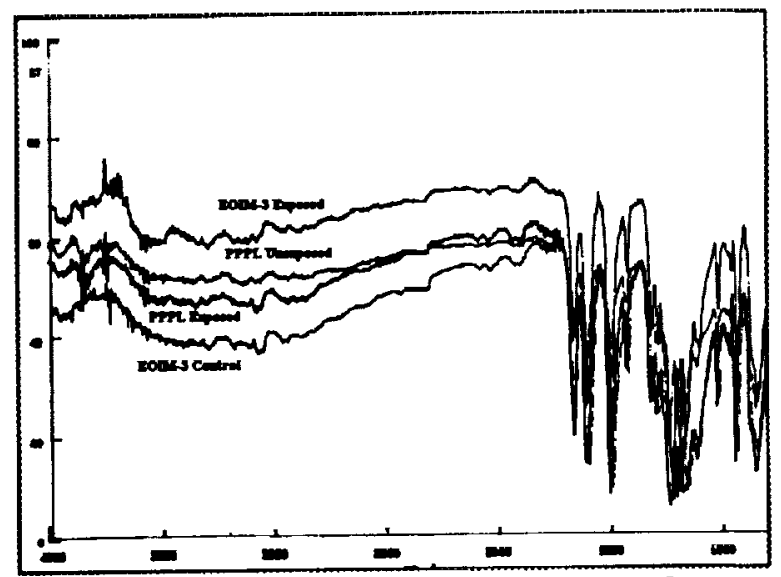

Figure 8. FTIR of EOIM-3 and PPPL exposed PEEK showing percent transmission as a function of wavenumber $\left(\mathrm{cm}^{-1}\right)$. 

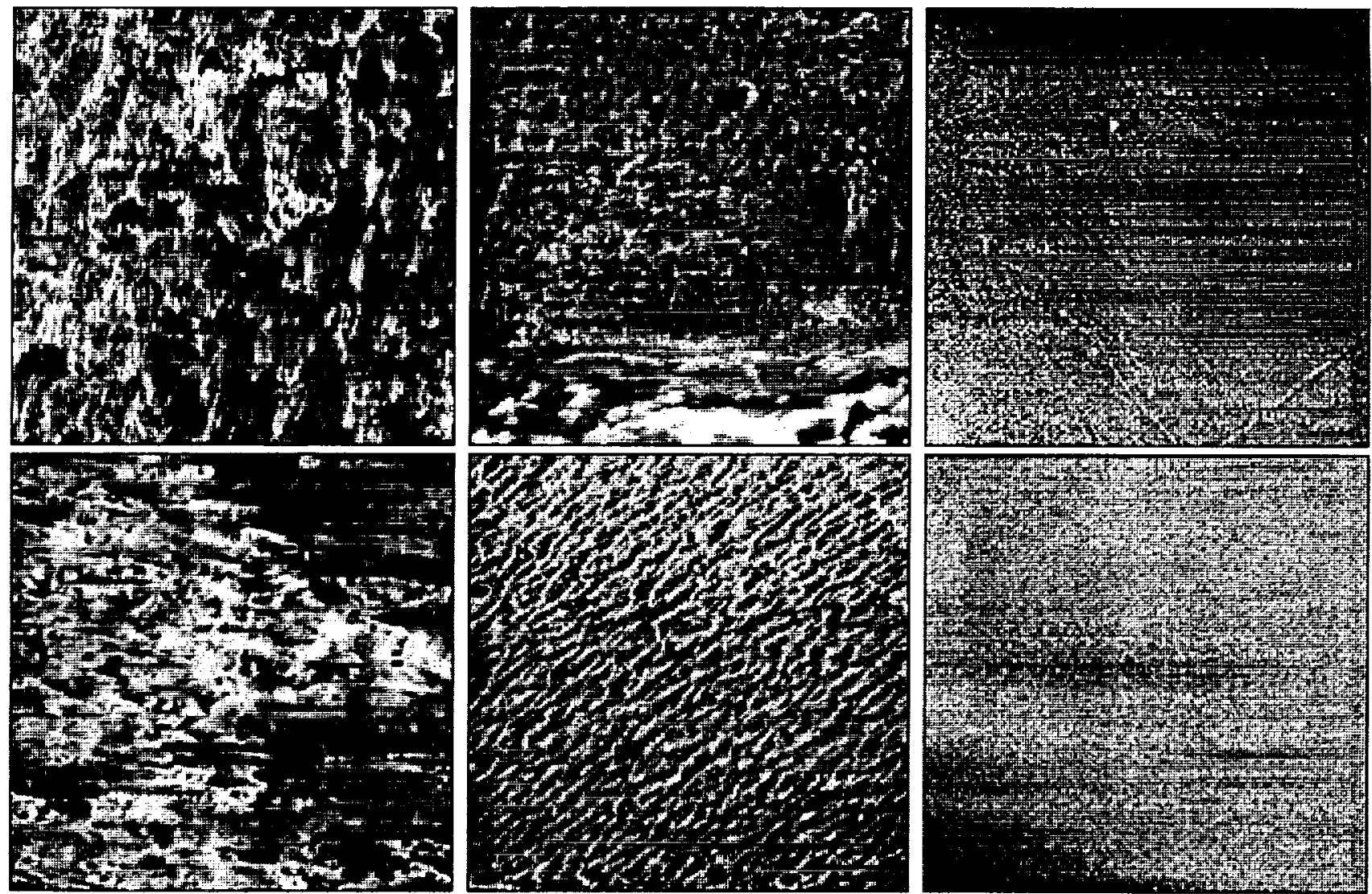

Figure 9. SEM photographs, $500 \mathrm{x}$, of exposed Halar (top row, left to right) from LDEF AO171, PPPL, EOIM-3 and exposed PEEK (bottom row, left to right) from LDEF AO171, PPPL, and EOIM-3. 


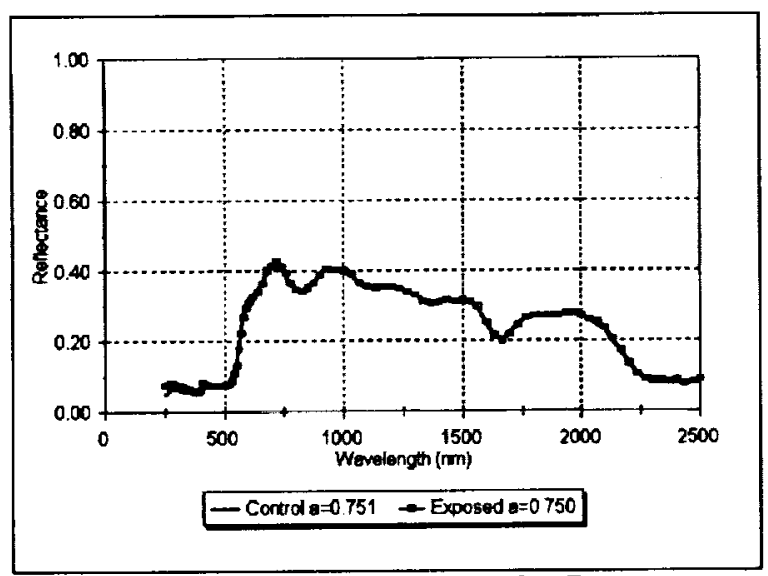

Figure 10. EOIM-3 S383 integrated reflectance as a function of wavelength.

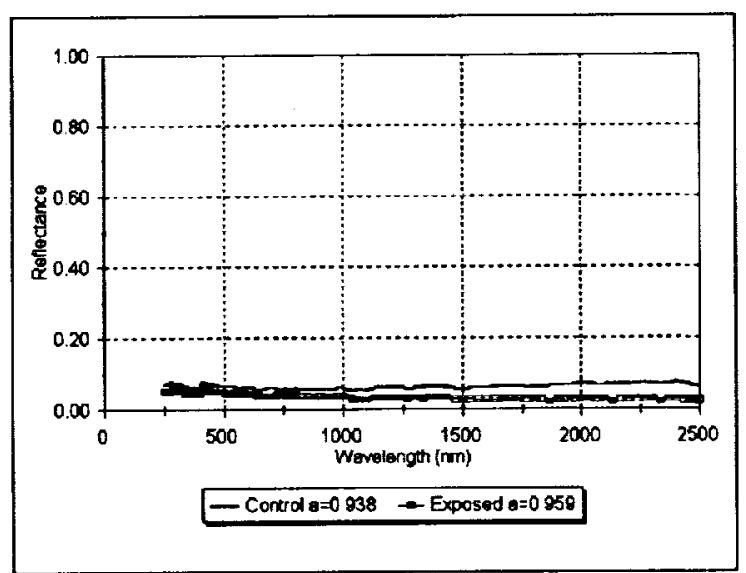

Figure 11. EOIM-3 Viton integrated reflectance as a function of wavelength.

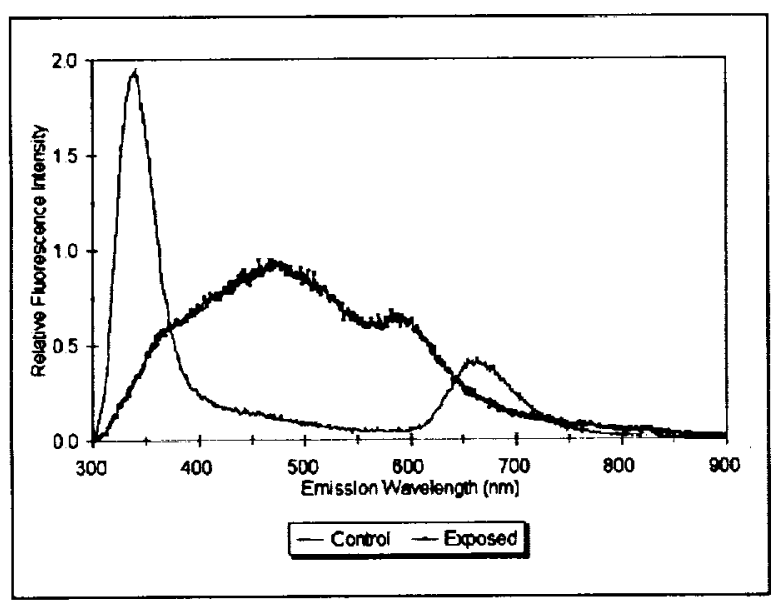

Figure 14. EOIM-3 S383 fluorescence scan showing the stimulated relative fluorescence emission as a function of emission wavelength due to low earth orbit exposure.

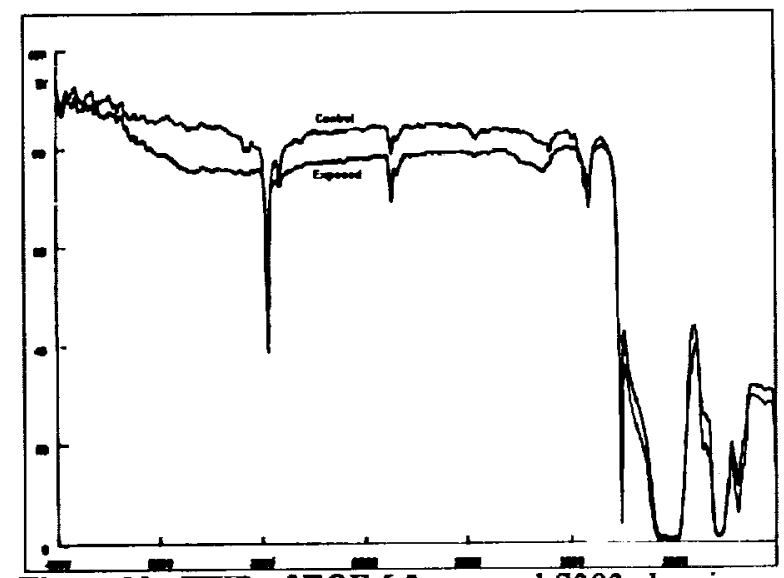

Figure 12. FTIR of EOIM-3 exposed S383 showing percent transmission as a function of wavenumber $\left(\mathrm{cm}^{-1}\right)$.

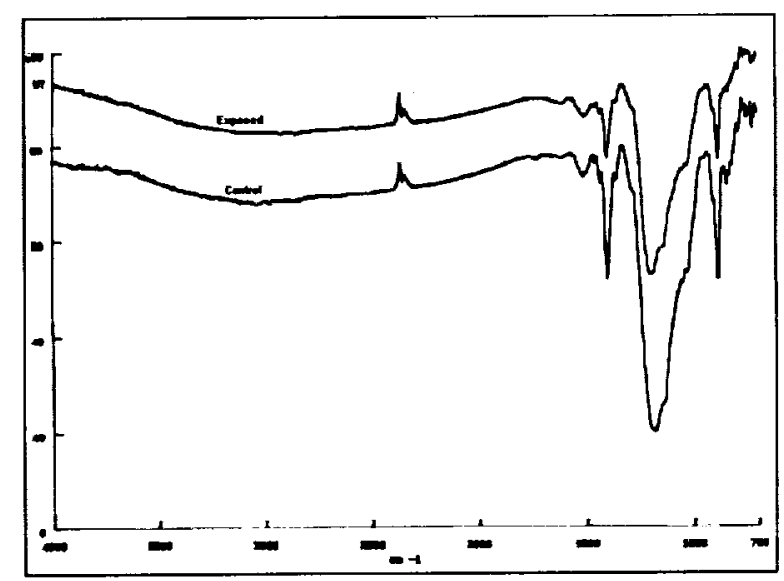

Figure 13. FTIR of EOIM-3 exposed Viton showing percent transmission as a function of wavenumber $\left(\mathrm{cm}^{-1}\right)$.

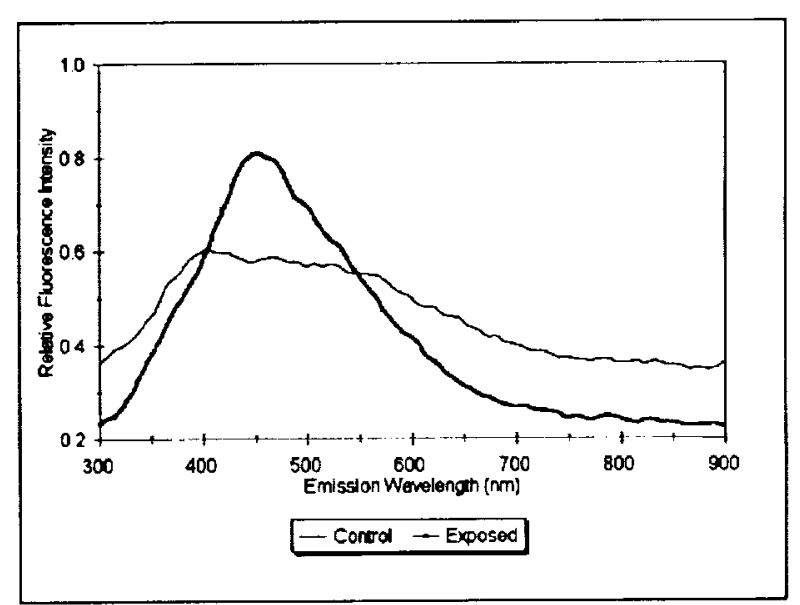

Figure 15. EOIM-3 Viton fluorescence scan showing the stimulated relative fluorescence emission as a function of emission wavelength due to low earth orbit exposure. 
.

, 